\title{
Implementation of innovative pulsed xenon ultraviolet (PX-UV) environmental cleaning in an acute care hospital
}

This article was published in the following Dove Press journal:

Risk Management and Healthcare Policy

22 January 2014

Number of times this article has been viewed

\author{
Lori Fornwalt ${ }^{1}$ \\ Brad Riddell ${ }^{1,2}$ \\ 'Departments of Infection Prevention \\ and Environmental Services, Trinity \\ Medical Centre, Birmingham, AL, \\ ${ }^{2}$ Environmental Services, Medical \\ University of South Carolina, \\ Charleston, SC, USA
}

\begin{abstract}
It is widely acknowledged that the hospital environment is an important reservoir for many of the pathogenic microbes associated with health care-associated infections (HAIs). Environmental cleaning plays an important role in the prevention and containment of HAIs, in patient safety, and the overall experience of health care facilities. New technologies, such as pulsed xenon ultraviolet (PX-UV) light systems are an innovative development for enhanced cleaning and decontamination of hospital environments. A portable PX-UV disinfection device delivers pulsed UV light to destroy microbial pathogens and spores, and can be used in conjunction with manual environmental cleaning. In addition, this technology facilitates thorough disinfection of hospital rooms in 10-15 minutes. The current study was conducted to evaluate whether the introduction of the PX-UV device had a positive impact on patient satisfaction. Satisfaction was measured using the Hospital Consumer Assessment of Healthcare Providers and Systems (HCAHPS) survey. In 2011, prior to the introduction of the PX-UV system, patient HCAHPS scores for cleanliness averaged $75.75 \%$. In the first full quarter after enhanced cleaning of the facility was introduced, this improved to $83 \%$. Overall scores for the hospital rose from $76 \%$ (first quarter, 2011) to $87.6 \%$ (fourth quarter, 2012). As a result of this improvement, the hospital received $1 \%$ of at-risk reimbursement from the inpatient prospective payment system as well as additional funding. Cleanliness of the hospital environment is one of the questions included in the HCAHPS survey and one measure of patient satisfaction. After the introduction of the PX-UV system, the score for cleanliness and the overall rating of the hospital rose from below the fiftieth to the ninety-ninth percentile. This improvement in the patient experience was associated with financial benefits to the hospital.
\end{abstract}

Keywords: HAIs, PX-UV, environmental cleaning, patient satisfaction

\section{Introduction}

Extensive publicity surrounding health care-associated infections (HAIs) has increased the level of public awareness of the risk of infection associated with hospitalization and the efforts being made by institutions to provide a "cleaner, safer environment". These raised levels of awareness may also cause anxiety and also impact on patient satisfaction. ${ }^{1}$

It is widely acknowledged that the hospital environment is an important reservoir for many of the pathogenic microbes associated with HAIs, ${ }^{2}$ and that environmental cleaning plays an important role in patient safety in health care facilities. Patients' satisfaction with the standards of cleanliness is recognized by the Centers for Medicare and Medicaid Services, and is one of the measures used in the assessment of hospital value-based purchasing and reimbursement of health care facilities. ${ }^{3}$ 
Patients need to understand the use and benefits of new technologies, and how these can improve their standard of care. Since 2005, the Hospital Consumer Assessment of Healthcare Providers and Systems (HCAHPS) survey (http:// www.hcahpsonline.org/home.aspx) has collected data on patients' experience of hospital care. The aim of the survey is to collect standardized information on hospital care, including levels of patient satisfaction, and consists of 32 questions encompassing nine key topics, including cleanliness of the hospital environment. The survey also includes four screener questions and seven demographic items, which are used for adjusting the mix of patients across hospitals and for analytical purposes. HCAHPS is administered to a random sample of adult inpatients between 48 hours and 6 weeks after discharge. The questionnaire is randomized and given by an outside vendor, with data blinded to the institution. Patients are surveyed throughout each month of the year, and at least 300 completed surveys over four calendar quarters must be achieved for each institution.

Methods of enhanced cleaning, such as ultraviolet (UV) light and hydrogen peroxide vapor, have been implemented in many facilities in the US and Europe. The use of these methods has been associated with decreased rates of HAIs. ${ }^{4}$ These new technologies are complementary to manual cleaning methods, and overcome some of the difficulties of decontaminating and disinfecting complex environments with multiple surfaces.

Trinity Medical Center is a 320-bed acute general medical and surgical hospital located in Birmingham, Alabama. Survey data for 2011 reported that 25,826 patients visited the hospital's emergency room and that there were 14,273 admissions (http://health.usnews.com/best-hospitals/area/al/ trinity-medical-center-6530161). In 2012, the Departments of Infection Prevention and Environmental Services investigated the use of new technologies to improve the cleanliness of the hospital environment. In selecting a method for enhancing the room-cleaning process, effectiveness in disinfection and eradication of pathogens, including spore-forming bacteria (eg, Clostridium difficile) were the most important factors. In addition, technology, system maintenance, efficiency, ease of use, and cost were considered. This resulted in the introduction of a pulsed xenon (PX)-UV light system for use in conjunction with the existing cleaning protocol. The portable PX-UV disinfection device delivers pulsed UV light to destroy microbial pathogens and spores, was used as an additional measure after rooms had been thoroughly cleaned by environmental staff, and has been shown to be more effective in reducing bacterial contamination than manual cleaning methods. ${ }^{5}$ Typically, the
PX-UV system (Xenex Disinfection Services, San Antonio, TX, USA) takes 5-15 minutes to disinfect a room.

The purpose of the current case study was to evaluate whether the introduction of a PX-UV disinfection device for the terminal cleaning of patient rooms had a positive impact on patient satisfaction. The device was introduced in conjunction with a patient-awareness campaign.

On September 1, 2012, a PX-UV disinfection program was implemented for the terminal cleaning of patient rooms. Prior to the introduction of the PX-UV system, the environmental services (EVS) management team gave presentations and demonstrations to the nursing and medical staff of the facility. In total, six training sessions were held with attendees from multiple specialties. The training included basic concepts of UV disinfection, safety essentials, room preparation, and use of the device. The EVS patient advocate provided information to patients about the use of PX-UV technology in the facility as part of an awareness program. Additional information was also provided, using flyers placed in common areas throughout the hospital and in patient rooms after disinfection with PX-UV. These flyers provided information on the use of PX-UV in the facility and its potential impact on patient safety. EVS staff also increased their visibility in the facility by wearing branded T-shirts.

\section{Materials and methods}

Patient-satisfaction scores were recorded using the HCAHPS survey on a quarterly basis after the introduction of the initiative and compared with the preintervention phase. HCAHPS scores for hospital cleanliness were followed for ten quarters prior to and three quarters after program implementation. Statistical analysis was done using the Wilcoxon rank-sum test.

\section{Results}

In the first and second quarters of 2010, hospital-cleanliness scores were $48 \%$ and $65 \%$, respectively. Prior to implementing the PX-UV system, patient satisfaction with cleanliness was below the 50th percentile in the first and fourth quarters of 2011 and averaged $75.75 \%$ (range $72 \%-79 \%$, Table 1). In 2012, for the first 6 months of the year, cleanliness scores were $77.5 \%$. After enhanced cleaning of the facility was introduced, this improved to $83.0 \%$ in the first full quarter (October to December 2012). The change in cleanliness scores was significant $(P=0.0221)$. Overall scores for the hospital rose from $76 \%$ (first quarter, 2011) to $87.6 \%$ (fourth quarter, 2012). Of note was that all the other nine parameters being measured, including communication and 
Table I Patient-satisfaction measures before and after the introduction of the Xenex pulsed xenon ultraviolet system in September 2012

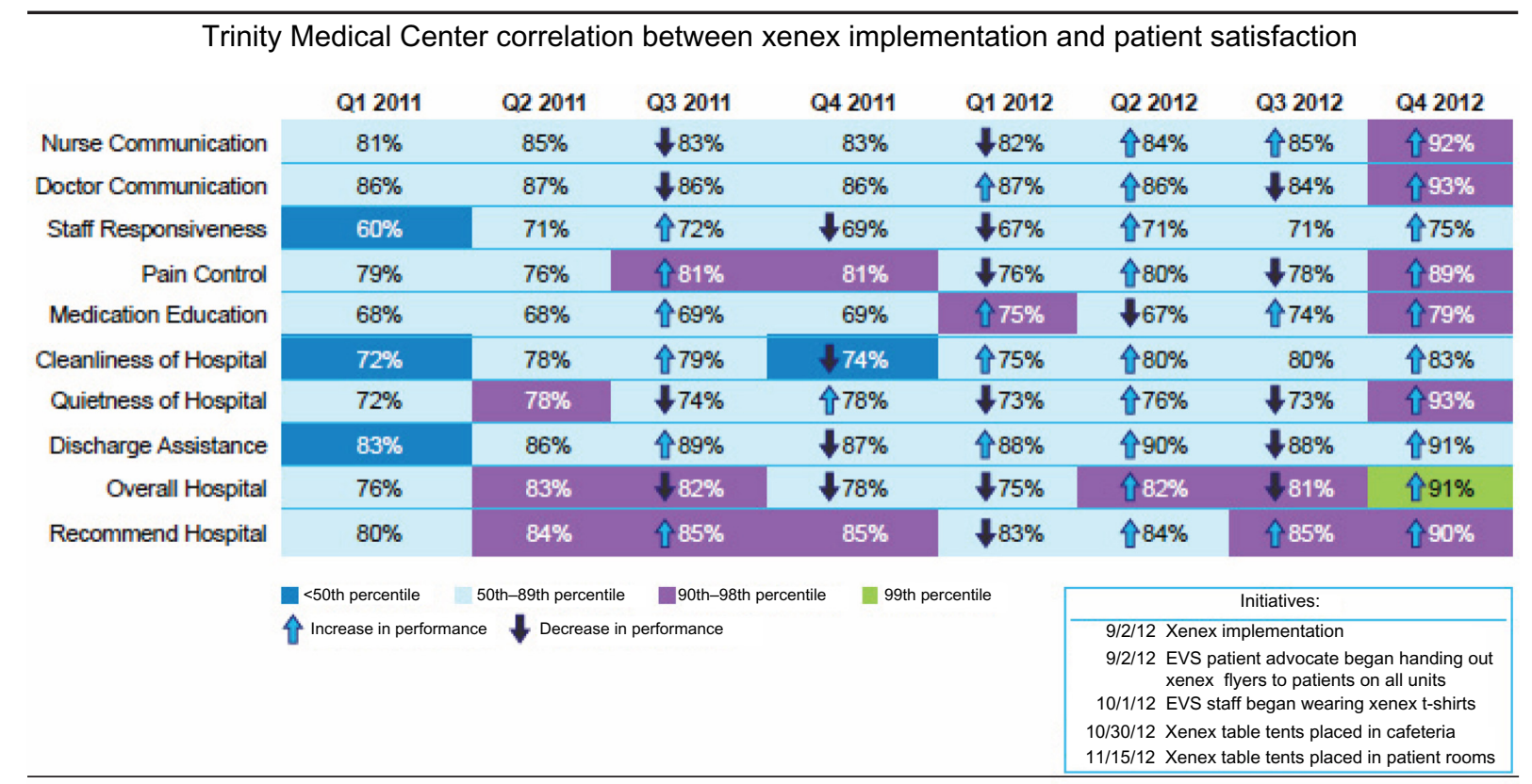

Note: Xenex Disinfection Services, San Antonio, TX, USA.

Abbreviations: Q, quarter; EVS, environmental services.

staff responsiveness, also improved over the same period. No other initiatives were introduced during this period, and there were no changes in staff or leadership.

As a result of this improvement, the hospital received $1 \%$ of at-risk reimbursement from the inpatient prospective payment system, as well as additional funding. At-risk reimbursement is a part of the Centers for Medicare and Medicaid Services' value-based purchasing program, which rewards health care facilities for providing high-quality care using a formula consisting of outcome measures and patient satisfaction. ${ }^{3}$

\section{Discussion}

Prior to the introduction of the PX-UV program, published results from the HCAHPA survey in August 2012 reported levels of patient satisfaction with the cleanliness of rooms and bedrooms as average (69\%) (http://health.usnews.com/besthospitals/area/al/trinity-medical-center-6530161/patientsatisfaction). In the seven quarters prior to the introduction of the PX-UV program, average patient satisfaction with the cleanliness of the facility had risen to $76.9 \%$. However, the improvement in patient-satisfaction scores to over $87.6 \%$ after the implementation of the PX-UV program and the implementation of awareness campaign highlights the role of communication and a team approach in creating a positive patient experience.

As the project was being implemented, patients took an interest and wanted to learn more. Some patients and a few physicians followed the cleaning technician around in order to observe the machine being used. One patient stated, "I am so happy I came to Trinity, because you are going the extra mile to make sure I don't get an infection!" It became apparent to the implementation team that patients were very observant, and the mere presence of an additional cleaning device made them feel safer by reducing the fear of acquiring an infection. Whilst the fear of infection may increase anxiety in patients, this study also demonstrates the benefits of patient education on levels of satisfaction. It highlights the importance of involving staff and patients from the beginning of an initiative. Other investigators have also reported the importance of education and involvement of EVS workers in reducing hospital-acquired infections and improving patient satisfaction. ${ }^{6,7}$

Some of the commercially available systems can take up to 90 minutes to disinfect a room, whereas the PX-UV system adopted takes 5-15 minutes per room, although the acquisition cost for the various types of devices is similar. In choosing advanced technologies, this is a factor that should be considered when purchasing capital equipment, because of the potential economic impact in terms of staffing and labor costs. The ability electronically to track the location of device use and the end user was also seen as an additional benefit in terms of being able to monitor the process. In addition, the system incorporates reflectors to focus UV light toward "high-touch" areas, such as handles and switches, which might otherwise be difficult to clean effectively. 
Cleanliness of the hospital environment is one of the questions included in the HCAHPS survey and one measure of patient satisfaction. After the introduction of the PX-UV system, the score for cleanliness and the overall rating of the hospital rose from below the 50th to the 99th percentile. This improvement in the patient experience was associated with considerable financial benefits to the hospital. As previously mentioned, patient-satisfaction scores are a component of the value-based purchasing program and an important element of health care provision under the Affordable Care Act, which initiated a set of health insurance reforms in $2010 .^{8}$ The higher the score, the more "at-risk" reimbursement you receive. This considered, the cleaning device was an excellent investment.

Cleaning practices should be tailored to clinical risk, and the design of both facilities and equipment. With the rise of complex electronic equipment within patient rooms and other areas, traditional cleaning methods that employ chemicals or liquids may be impractical.

Although this study has its limitations in that it is a preand postintervention design in which other factors cannot be controlled, it does however demonstrate the successful implementation of a new technology in a practical situation. The study took place in the clinical setting as part of routine quality improvement to environmental decontamination, and was not controlled for other changes that may have occurred in the hospital over the assessment period. The PX-UV system may be a useful addition in the quest to create a cleaner environment and improve patients' experience of hospitalization, although further study is needed to confirm these data, and the cleanliness scores for the hospital continue to be monitored.

\section{Conclusion}

Cleanliness of the hospital environment is one element contributing to patient-satisfaction scores. After the introduction of a PX-UV cleaning system (which had been implemented in conjunction with staff training and patient education), overall patient satisfaction improved from an average $75.75 \%$ in 2011 to $83 \%$ in the fourth quarter of 2012 .

\section{Author contributions}

The authors confirm that they have complied with the International Committee of Medical Journal Editors (ICMJE) guidelines and have contributed equally to the manuscript.

\section{Acknowledgments}

The editorial support of Innovative Strategic Communications, LLC in the preparation of this manuscript is acknowledged. Funding for this editorial support was provided by Xenex Disinfection Services, LLC.

\section{Disclosure}

Neither author has received gifts or monetary compensation from Xenex or any companies associated with the research presented. The authors report no other conflicts of interest in this work.

\section{References}

1. Morgan DJ, Diekema DJ, Sepkowitz K, Perencevich EN. Adverse outcomes associated with contact precautions: a review of the literature. Am J Infect Control. 2009;37(2):85-93.

2. Donskey CJ. Does improving surface cleaning and disinfection reduce health care-associated infections? Am J Infect Control. 2013; 41(Suppl 5):S12-S19.

3. Centers for Medicare and Medicaid Services. Hospital value-based purchasing. 2013. Available from: http://www.cms.gov/Medicare/ Quality-Initiatives-Patient-Assessment-Instruments/hospital-valuebased-purchasing/index.html. Accessed August 20, 2013.

4. Davies A, Pottage T, Bennett A, Walker J. Gaseous and air decontamination technologies for Clostridium difficile in the healthcare environment. J Hosp Infect. 2011;77(3):199-203.

5. Stibich M, Stachowiak J, Tanner B, et al. Evaluation of a pulsedxenon ultraviolet room disinfection device for impact on hospital operations and microbial reduction. Infect Control Hosp Epidemiol. 2011;32(3):286-288.

6. Matlow AG, Wray R, Richardson SE. Attitudes and beliefs, not just knowledge, influence the effectiveness of environmental cleaning by environmental service workers. Am J Infect Control. 2012;40(3): 260-262.

7. Jennings A, Sitzlar B, Jury L. A survey of environmental service workers' knowledge and opinions regarding environmental cleaning. Am J Infect Control. 2013;41(2):177-179.

8. US Government. The Patient Protection and Affordable Care Act. Public Law 111-148. 124 Stat 119. 2010. Available from: http://www.gpo.gov/ fdsys/pkg/PLAW-111pub1148/pdf/PLAW-111publ148.pdf. Accessed October 9, 2013.

\section{Publish your work in this journal}

Risk Management and Healthcare Policy is an international, peerreviewed, open access journal focusing on all aspects of public health, policy, and preventative measures to promote good health and improve morbidity and mortality in the population. The journal welcomes submitted papers covering original research, basic science, clinical \& epidemio-

\section{Dovepress}

logical studies, reviews and evaluations, guidelines, expert opinion and commentary, case reports and extended reports. The manuscript management system is completely online and includes a very quick and fair peerreview system, which is all easy to use. Visit http://www.dovepress.com/ testimonials.php to read real quotes from published authors. 